\title{
Chapter 5 \\ The Importance of Instructional Quality for the Relation Between Achievement in Reading and Mathematics
}

\author{
Guri A. Nortvedt, Jan-Eric Gustafsson and Anne-Catherine W. Lehre
}

\begin{abstract}
Students gain access to mathematical tasks through reading; consequently, low-performing readers generally perform low in mathematics. High quality instruction might help students develop comprehension strategies for reading mathematics that weakens the relationship between reading and mathematics skills. The main aim of this chapter is to investigate how instructional quality might moderate the relationship between reading and mathematics achievement. Analyzing data from 37 countries and benchmark participants who applied the same sample for TIMSS 2011 and PIRLS 2011, two different models were fitted to the data for each educational system: (1) a two-level confirmatory factor analysis (CFA) model for instructional quality and the correlation between instructional quality and reading and mathematics achievement at student and class levels, and (2) a two-level random slopes model in which the slope variation across classrooms was related to class-level instructional quality. In all educational systems, there was a strong positive correlation between reading comprehension and mathematics achievement. Further, a positive relation between instructional quality and mathematics and reading achievement was observed in a number of countries. The analysis of how instructional quality moderated the relationship between mathematics and reading was inconclusive. The influence of reading comprehension on mathematics achievement was significantly moderated by instructional quality in only six countries; nonetheless, the driving hypothesis should not be rejected.
\end{abstract}

\footnotetext{
G.A. Nortvedt ( $\square)$

Department of Teacher Education and School Research,

University of Oslo, Oslo, Norway

e-mail: guri.nortvedt@ils.uio.no

\section{J.-E. Gustafsson}

Department of Education and Special Education, University of Gothenburg,

Gothenburg, Sweden

e-mail: jan-eric.gustafsson@ped.gu.se

J.-E. Gustafsson · A.-C.W. Lehre

Faculty of Educational Sciences, Centre for Educational Measurement at the University of Oslo (CEMO), Oslo, Norway

e-mail: a.c.w.g.lehre@ils.uio.no 
Keywords Instructional quality - Mathematics - Reading - Two-level structural equation modeling moderation models - Trends in Mathematics and Science Study (TIMSS 2011) and Progress in International Reading Literacy Study (PIRLS) 2011

\subsection{Rationale}

Mathematics achievement may be influenced by reading comprehension and instructional quality. Across the world, a major mandate for primary school teachers is to introduce all their young students to reading and mathematics, thus constructing the foundations for lifelong learning. The main aim of mathematics education is to develop students' mathematical competence (Niss and Højgaard 2011), namely to prepare students for further education and participation in society. Students should be prepared to use their mathematical competence in a variety of situations, to pose and solve problems, and to communicate and reason mathematically. For countries that participate in TIMSS, being able to solve both pure and applied mathematical problems is recognized as an important skill, which is in line with the definition of mathematical competence.

Reading plays a particular role in mathematical problem solving. Before students can apply their mathematical knowledge to solve a textbook or assessment item, they first need to access the problem to be solved, to understand it, and to plan how to proceed. This is generally accepted for problem solving and modeling (see, for instance, Lesh and Zawojewski 2007). Although the necessity for text comprehension is less recognized for given problems, students need to be able to read and comprehend symbolic mathematical language (Niss and Højgaard 2011). Consequently, all mathematical problem solving may be assumed to rest on students' reading skills as well as their mathematical proficiency, because they access the mathematical content through reading activities.

In primary school reading instruction, a shift from learning to read to reading to learn is usually seen around grade four (Murnane et al. 2012; Snow 2002). In the first primary school grades, a strong focus on first learning to read, that is, to decode, is followed by instruction directed toward developing students' reading comprehension in higher grades, to allow the students to apply their reading skills in other learning activities. Although primary school teachers' approaches to reading instruction differ, more effort is likely directed toward improving students' word-decoding skills than toward reading comprehension. Murnane et al. (2012) claimed that reading instruction is mainly based on literary texts, and less on science, civic, or social studies texts. Further, they claimed that the selected texts allow students few possibilities to grapple with deep comprehension. It may be questioned if such a focus benefits students when it comes to comprehending text presented in mathematics, where texts are typically short and need translated from symbolic language to everyday language. 
Österholm (2005) found that the use of mathematical symbols was challenging to students in transition from secondary school to college. Language or text elements that demand deep reading strategies, such as the use of keywords, challenging syntax, or irrelevant information, influence students' success in solving mathematical problems, as is well-documented in prior research on primary school students (Abedi and Lord 2001; Cummins et al. 1988; Roth 2009; Säljö et al. 2009; Thevenot et al. 2007; Verschaffel et al. 2000; Vicente et al. 2007). Fuchs et al. (2015) even proposed that mathematical word problem solving is a form of text comprehension.

Another factor contributing to the difficulties students experience is the common belief that solving mathematical problems is about "doing numbers" (Fuentes 1998; Nortvedt 2010). This view might be shared by teachers and students. Previous research has demonstrated that teachers are concerned about the amount of text in mathematical assessments. When students struggle to solve word problems, teachers blame the amount of text, rather than recognizing students' lack of text comprehension strategies (Pearce et al. 2012). Teachers need to recognize the relationship between reading and mathematics and pay specific attention to it through the teaching-learning opportunities they offer their students. Giving special attention to reading might help students improve their mathematical problem solving (Glenberg et al. 2012; Thevenot et al. 2007).

We aim to investigate how instructional quality might moderate the relationship between reading and mathematics. A strong positive relationship between reading and mathematics indicates that students who are low performing in PIRLS are also most likely to perform low in TIMSS. Our driving hypothesis is that high-quality teaching can contribute to weakening the relationship between reading skills and mathematics achievement; that instruction might help grade four students overcome difficulties comprehending the items given in the TIMSS 2011 mathematics assessment. Three research questions are addressed:

(1) What is the class-level relationship between reading and mathematics achievement?

(2) What is the class-level relationship between instructional quality and reading comprehension, and between instructional quality and mathematics achievement?

(3) To what extent does instructional quality moderate the relationship between reading and mathematics achievement?

\subsection{The Influence of Reading on Mathematics Achievement}

Previous research has demonstrated a moderate to strong positive relationship between reading and mathematics achievement (Adelson et al. 2015; Bernardo 2005; Moreau and Coquin-Viennot 2003; Nortvedt 2011; Vilenius-Tuohimaa et al. 
2008). Typically, a correlation of $0.5-0.7$ is observed at the student level. Most studies investigate the relationship between reading comprehension measures and some aspect of numeracy or mathematical word problem solving (Cummins et al. 1988; Palm 2008; Reusser and Stebler 1997; Thevenot et al. 2007; Verschaffel et al. 2000; Vilenius-Tuohimaa et al. 2008). Björn et al. (2014) found that text comprehension in grade four predicts mathematical word problem solving skills in secondary school. The more technical aspect of reading, namely decoding, is emphasized less often. However, even controlling for decoding, reading comprehension and mathematics have a positive relationship (Vilenius-Tuohimaa et al. 2008). The importance of reading comprehension was supported by Vista (2013), who, in a longitudinal study of Grade 3-8 Australian students, found that reading comprehension skills partially mediate the relation between problem solving ability and mathematical growth. It might be concluded that students who struggle to read will most likely also struggle to solve mathematical tasks.

Reading attention might also play a role in students' comprehension of mathematical tasks. Fuentes (1998) claimed that much of the issue with mathematical problem solving stems from students' beliefs about this activity. Many students believe that mathematics is about "doing numbers." Consequently, careful reading of the test items to unfold their underlying mathematical structure and identifying what to do is not the students' primary concern. Instead, they engage in what Verschaffel et al. (2000) termed "the word problem game," in which students typically identify an operation based on applying keywords as operation words instead of relationally. For instance, in word problems such as "Jane and Mark have 57 Euros altogether. Mark has 7 more Euros than Jane. How much does Jane have?" students who apply surface strategies typically treat 'altogether' and 'more' as operation words, signaling that the correct operation is addition. They will get 64 Euros as their solution to the item. Students who apply deep reading strategies will more likely treat the two keywords as relational words that explain the relationships between quantities and persons and get 25 Euros as the answer to their calculations.

Although the relationship between reading comprehension and mathematical performance is strong at the student level, Adelson et al. (2015) found that the relationship was even stronger at the school level, which they interpreted as indicating that the quality of instruction matters. They consequently proposed that reading strategies should be taught in mathematics classrooms. Indications that such interventions might be fruitful were documented by Glenberg et al. (2012). Initiating a small-scale intervention, Glenberg et al. (2012) improved students' mathematical performance by training Grade three and four students $(n=58)$ to apply a digital tool that assisted them in creating embodied mental models of problem texts, by manipulating on-screen pictures. Trained students, to a larger extent than the control group $(n=39)$, avoided using irrelevant numerical information in their solutions to the mathematical word problems, even without access to the tool. This indicates that training students to pay specific attention to content may later help them to identify the underlying mathematical structure in a problem, and to more easily discriminate between relevant and irrelevant information in the problem context. 
Both successful and erroneous strategies displayed in student work in secondary or college education might stem from how students comprehend mathematical tasks during the primary school years. Nortvedt (2011), for instance, proposed that lower secondary school students with above-average mathematics and below-average reading achievement to some extent compensate for their weaker reading comprehension by recognizing stereotypical arithmetic word problems. However, at the same time, these students make mistakes more frequently than their peers with above-average reading and numeracy skills, because the students treat key words such as "altogether," "less," or "more" as signal words that indicate appropriate mathematical operations instead of as relational statements. Students at all ability levels make such mistakes, and it is likely that they are due to transferring simple surface strategies learned from early instruction, when word problems could be solved by applying one of the four operations, a well-known phenomenon (see, for instance, Cummins et al. 1988). That is, primary school mathematics education might support students in playing the "number game." In addition, students of all ages tend to suspend sense-making and work more on solving problems than on comprehending them (Inoue 2005; Palm 2008; Schoenfeld 1992).

Lack of sense-making and overreliance on naïve methods might result from teaching-learning activities, and thus indicate issues with the quality of instruction. Graeber et al. (2012) analyzed video data from 69 teachers of grade four and six students, evaluating a total of 550 reading lessons and 600 mathematics lessons, to compare the quality of instruction in the two school subjects. They found that, overall, teachers who offered cognitively demanding teaching in the mathematics lessons were not always efficient reading teachers. Only $12 \%$ of the teachers offered high-quality instruction in both subjects, offering teaching with high cognitive demand in terms of the quality of teacher questioning and content offered (i.e., demand of tasks and lesson content). A second important observation made by Glenberg et al. (2012) was that mathematics instruction seemed more consistent than reading instruction. For instance, while introducing reading material that had high cognitive demand, the teachers often failed to engage students in activities that reflected this level.

\subsubsection{Relationships Among Reading and Mathematics: TIMSS and PIRLS 2011}

When designing TIMSS 2011 and PIRLS 2011, many countries saw the opportunity to link these two studies to collect extensive information about the quality of instruction at the end of the early years of primary school (Mullis and Martin 2013). In total, 34 countries and three benchmarking entities took the opportunity to have the same grade four students take both assessments. 
In PIRLS, reading achievement is reported on a scale comprising four benchmark levels. In total, $95 \%$ of the grade four students achieve at or above the lowest benchmark, indicating that they can "locate and retrieve information from different parts of the text" (Mullis et al. 2012b). Analysis showed that reading competence is required for many of the tasks in grade four mathematics and science (Mullis et al. 2013). Mullis et al. (2013) divided the students into three groups according to their reading proficiency, and further analysis showed that better readers outperformed average readers, and average readers outperformed poor readers in mathematics. For most countries, better readers had a significant advantage over poor readers when doing mathematical tasks that had a high reading demand. Only the best readers performed well across all mathematical questions independently of the tasks' reading demand. Less proficient readers performed relatively better on items that had a low reading demand than on items that had a high reading demand. In some countries (Austria, Chinese Taipei, Croatia, Hungary, Italy, Lithuania, Northern Ireland, Qatar, Romania, the Russian Federation, Saudi Arabia, Singapore, and the United Arab Emirates), the difference in mathematics achievement between good and poor readers was significant (Mullis et al. 2013).

Although a positive well-equipped school environment provides important support for teaching and learning, teacher quality is essential (Martin et al. 2013). Classroom teachers provide instruction directly to their students and thus influence the students' learning environment. Teachers contribute positively when they are well-prepared and provide effective engaging instruction. Students engaged in their reading or mathematics lessons had higher scores on TIMSS and PIRLS 2011, compared to students who were "somewhat engaged" or "not engaged" in their lessons. Student engagement in reading, mathematics, and science was positively related to achievement in at least one subject in 17 countries and in all three subjects in nine countries.

To summarize, although there is a strong relationship between reading and mathematics outcomes at the student level, the relationship is even stronger at the class level (Adelson et al. 2015). Errors students make might stem from their prior experiences in the mathematics classroom and from too little focus on strategies for comprehending mathematical text. For instance, students reading at an intermediate level on PIRLS might make straightforward inferences from the text they read (Mullis et al. 2012b). However, mathematical problems might demand more advanced reading strategies. Much teaching does not offer a high cognitive demand (Graeber et al. 2012), which is most likely necessary for students to develop good comprehension skills in reading and mathematics. Glenberg et al. (2012) found that training students in comprehension strategies for reading mathematical word problems helped students develop strategies for reading mathematical word problems and become more successful problem solvers. Thus, prior research supports our hypothesis that high instructional quality might weaken the strong relationship between reading comprehension and mathematics achievement. 


\subsection{Method}

Using data from the joint TIMSS and PIRLS 2011 database (available from http:// timssandpirls.bc.edu/timsspirls2011/international-database.html), grade four students' outcomes in mathematics and reading were analyzed, applying multilevel structural equation modeling (SEM) with random slopes to investigate the moderating effects of instructional quality on the relationship between reading and mathematics outcomes. We aimed to capture variation across classrooms in the slope of the regression of mathematics achievement on reading achievement in a class-level latent variable and to investigate whether classroom instructional quality was negatively related to slope.

\subsubsection{PIRLS 2011 and TIMSS 2011}

PIRLS is an international, large-scale survey of students' reading literacy. First conducted in 2001, PIRLS assesses students in grade four every fifth year (Mullis et al. 2012b). Reading literacy is defined as

The ability to understand and use those written language forms required by society and/or valued by the individual. Young readers can construct meaning from a variety of texts. They read to learn, to participate in communities of readers in school and everyday life, and for enjoyment (Mullis et al. 2009a, p. 11).

Three aspects of reading literacy are assessed: (1) purpose of reading, (2) processes of comprehension, and (3) reading behaviors and attitudes. In the analysis in this chapter the achievement data from the reading test is taken as a measure of students' reading comprehension. In the following sections, we consequently refer to reading comprehension instead of reading literacy.

TIMSS and PIRLS use a matrix-sampling design, where each student is administered only a subset of the texts and associated items. All achievement scores are expressed on a common scale in the form of "plausible values," which are multiple imputed scores that take advantage of all available responses to test items and background variables (see, for instance, von Davier et al. 2009). There were five plausible values, and the information in all five was taken advantage of with the imputation procedure implemented in Mplus 7 (Muthén and Muthén 1998-2012).

\subsubsection{Sample}

In total, 34 countries and three benchmark participants applied the same sample for TIMSS and PIRLS 2011 (Martin and Mullis 2013), implying that a sampled student participated in both studies. These students constitute the sample used for the analyses reported in this chapter. 


\subsubsection{Constructs}

\section{Reading comprehension}

The reading comprehension construct in PIRLS 2011 comprises four types of comprehension processes: (1) focus on and retrieve explicitly stated information, (2) make straightforward inferences, (3) interpret and integrate ideas and information, and (4) examine and evaluate content, language, and textual elements (Mullis et al. 2009a, p. 13).

\section{Mathematics achievement}

The grade four TIMSS 2011 assessment of student achievement in mathematics is used as a measure of students' mathematical competence in solving pure (given) and applied (word problems) mathematical tasks (Mullis et al. 2009b).

\section{Instructional quality}

Six parallel questions from the student questionnaires on TIMSS and PIRLS were used to measure instructional quality. All were four-category Likert items ranging from "disagree a lot" to "agree a lot," introduced by the statement "How much do you agree with these statements about your mathematics lessons/reading lessons?":

- MATEXP/RDTEXP: I know what my teacher expects me to do

- MATEASY/RDTEASY: My teacher is easy to understand

- MATISAY/RDTISAY: I am interested in what my teacher says.

In one measurement model, two instructional quality (InQua) factors were included: InQua-Math and InQua-Read. However, as the class-level correlation was close to unity in most countries, the two factors were collapsed into a global measure of instructional quality, InQuaB, which was related to all six items. Thus, based on the instructional quality items in the mathematics and reading questionnaire, a global class-level instructional quality measure (InQuaB) was estimated, while for the student level there were two correlated InQua variables, one for mathematics and one for reading. The factor loadings of the indicators of instructional quality on InQuaB were generally very high, often close to unity, even though there were some differences between educational systems.

Researchers have recently started to take advantage of students' ratings as a source of information about instructional quality. Although a single student's rating is not very dependable, the assessment becomes more reliable and valid when done by a whole class of students and when applied to more than one subject matter area. Scherer and Gustafsson (2015) used student questionnaire items concerning TIMSS and PIRLS 2011 reading, mathematics, and science teaching from three countries and demonstrated that a two-level latent variable modeling approach could separate different aspects of instructional quality. Here, we have adopted a similar, but simpler, approach that investigated only instructional quality in reading and mathematics. 


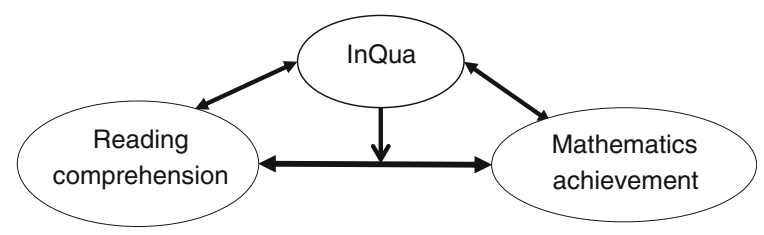

Fig. 5.1 Proposed research model describing the relationship between reading comprehension and mathematics achievement and the influence of InQua on this relationship at the class level

As student ratings are aggregated to the classroom level and both the mathematics and reading scales are included, we argue that applying data on instructional quality from the student questionnaire is valid for the analyses performed.

\subsubsection{Analysis}

Two-level SEM, distinguishing between student and class levels, was applied to investigate the relations among reading comprehension, mathematics achievement, and instructional quality. All five plausible values were included in the analysis of reading comprehension and mathematics achievement. Only class-level results are reported as this level is the focus of our study (Fig. 5.1).

First, a two-level confirmatory factor analysis (CFA) model for InQuaB and for the correlations between InQuaB and reading and mathematics achievement at the student and class levels was fitted. A separate model was fitted to the data for each educational system because metric invariance could not be established across all countries. These models all converged and fitted the data well, with model fit ranging from $C F I=0.972, T L I=0.948, R M S E A=0.051, S R M R_{\text {within }}=0.038$, $S R M R_{\text {between }}=0.097$ (Chinese Taipei) to $C F I=0.998, T L I=0.996, R M S E A=$ $0.012, S R M R_{\text {within }}=0.009$, and $S R M R_{\text {between }}=0.066$ (Lithuania).

The second model was a two-level random slopes model, in which the slope variation for the regression of mathematics on reading comprehension across classrooms was related to class-level InQua in each educational system.

\subsection{Results}

We aimed to investigate the relationship between reading comprehension and mathematics achievement and how this relationship is influenced by InQuaB. We first report results from the two-level CFA model for instructional quality, investigating the correlation between InQuaB and reading and mathematics achievement at the class level. We then report results from the random slopes model focusing on the slope variation across classrooms as a function of InQuaB. 


\subsubsection{Relationship Among Mathematics Achievement, Reading Comprehension, and Instructional Quality}

With the exception of Chinese Taipei, Singapore, Hong Kong, Malta, and Morocco, the average student score was higher in reading than in mathematics. At the classroom level, the correlation between mathematics and reading achievement ranged from 0.824 to 0.996 and was highly significant for all countries (Table 5.1). With the exception of three countries and one benchmark participant, the correlation between reading and mathematics was larger than 0.90. This is in good agreement with previous research (for instance, Adelson et al. 2015).

The relationship between InQuaB and mathematics achievement and reading comprehension at the class level was positive and significant for a number of educational systems (Australia, Botswana, Chinese Taipei, Dubai, Georgia, Hong Kong, Malta, Morocco, Oman, Portugal, Qatar, Romania, Singapore, and the United Arab Emirates), indicating that high-achieving classes value their teachers more than low-achieving classes in these countries (Table 5.1). In Azerbaijan and Saudi Arabia, the relationship was positive and significant for either mathematics or reading.

In Poland and Honduras, the correlation was negative and significant for mathematics and reading. Thus, in these two countries, low-achieving classes value their teacher and the instructional quality more than high-achieving classes do. The fact that low-performing classes tended to be more positive in their assessment of their teacher is apparent in other countries as well. In a number of educational systems (Austria, Croatia, the Czech Republic, Finland, Germany, Ireland, Quebec, the Russian Federation, Slovenia, the Slovak Republic, Spain, and Sweden) the overall correlation with InQuaB was negative, although not significant for reading achievement, mathematics achievement, or both. In addition, a number of educational systems had a non-significant positive relationship (Abu Dhabi, Hungary, Iran, Italy, Lithuania, Northern Ireland, and Norway). These non-significant relationships, both positive and negative, between InQua and achievement make some of the observed patterns difficult to interpret.

\subsubsection{The Influence of Instructional Quality on the Relationship Between Reading Comprehension and Mathematics Achievement}

In the final step, random slopes models were estimated by regressing the latent slope variable on InQuaB. All models converged nicely, but the regression coefficient was significant in only six cases (Table 5.1). This is probably because the statistical power was low in these models due to a limited number of students in each classroom. According to the driving hypothesis, the estimate of the regression coefficient slope should be negative if instructional quality weakens the influence of 
Table 5.1 International averages of mathematics and reading achievement for 37 educational systems in TIMSS 2011 and PIRLS 2011 grade four, along with relationships between mathematics achievement, reading achievement, and instructional quality

\begin{tabular}{|c|c|c|c|c|c|c|}
\hline \multirow[t]{2}{*}{$\begin{array}{l}\text { Educational } \\
\text { system }\end{array}$} & \multicolumn{2}{|c|}{$\begin{array}{l}\text { International } \\
\text { averages }\end{array}$} & \multicolumn{3}{|c|}{ Measurement models } & \multirow{2}{*}{$\begin{array}{l}\begin{array}{l}\text { Random slope } \\
\text { models }\end{array} \\
\text { Slope on } \\
\text { InQuaB }\end{array}$} \\
\hline & Math & Read & $\begin{array}{l}\text { Math with } \\
\text { read }\end{array}$ & $\begin{array}{l}\text { Math with } \\
\text { InQuaB }\end{array}$ & $\begin{array}{l}\text { Read with } \\
\text { InQuaB }\end{array}$ & \\
\hline Azerbaijan & 463 & 462 & $0.878^{* *}$ & $0.292 * *$ & 0.195 & -0.110 \\
\hline Australia & 516 & 527 & $0.990 * *$ & $0.220 * *$ & $0.222 * *$ & 0.017 \\
\hline Austria & 508 & 529 & $0.974 * *$ & -0.169 & -0.253 & $0.024 *$ \\
\hline Botswana & 419 & 419 & $0.983 * *$ & $0.692 * *$ & $0.699 * *$ & -0.089 \\
\hline Chinese Taipei & 591 & 533 & $0.966^{* *}$ & $0.351 *$ & $0.334 *$ & 0.089 \\
\hline Croatia & 490 & 553 & $0.957 * *$ & -0.102 & -0.090 & $-0.116^{* *}$ \\
\hline Czech Republic & 511 & 545 & $0.979 * *$ & 0.002 & -0.028 & $0.069 * *$ \\
\hline Finland & 545 & 568 & $0.967 * *$ & -0.021 & -0.014 & $-0.016 * *$ \\
\hline Georgia & 450 & 488 & $0.970 * *$ & $0.539 * *$ & $0.499 * *$ & -0.158 \\
\hline Germany & 528 & 541 & $0.988^{* *}$ & -0.042 & -0.046 & 0.163 \\
\hline Honduras & 396 & 450 & $0.950 * *$ & $-0.296^{*}$ & $-0.390 * *$ & 0.034 \\
\hline Hong Kong & 602 & 571 & $0.969 * *$ & $0.527 * *$ & $0.512 * *$ & 0.002 \\
\hline Hungary & 515 & 539 & $0.989 * *$ & 0.018 & 0.011 & 0.181 \\
\hline Iran & 431 & 457 & $0.948 * *$ & 0.077 & 0.155 & -0.098 \\
\hline Ireland & 527 & 552 & $0.928 * *$ & -0.048 & -0.082 & 0.182 \\
\hline Italy & 508 & 541 & $0.931 * *$ & 0.207 & 0.221 & 0.043 \\
\hline Lithuania & 534 & 528 & $0.987 * *$ & 0.130 & 0.124 & 0.195 \\
\hline Malta & 496 & 477 & $0.938^{* *}$ & $0.426^{* *}$ & $0.430 * *$ & 0.012 \\
\hline Morocco & 335 & 310 & $0.938 * *$ & $0.319 * *$ & $0.344 * *$ & 0.029 \\
\hline Oman & 385 & 391 & $0.957 * *$ & $0.356^{* *}$ & $0.380 * *$ & -0.056 \\
\hline Norway & 498 & 507 & $0.955^{* *}$ & 0.195 & 0.244 & 0.167 \\
\hline Poland & 481 & 526 & $0.987 * *$ & $-0.281 *$ & $-0.290 *$ & 0.144 \\
\hline Portugal & 532 & 541 & $0.977 * *$ & $0.290 * *$ & $0.265^{* *}$ & 0.017 \\
\hline Qatar & 413 & 425 & $0.971 * *$ & $0.333^{* *}$ & $0.409 * *$ & -0.323 \\
\hline Romania & 482 & 502 & $0.958^{* *}$ & $0.303 * *$ & $0.352 * *$ & 0.021 \\
\hline $\begin{array}{l}\text { The Russian } \\
\text { Federation }\end{array}$ & 542 & 569 & $0.930 * *$ & -0.041 & -0.120 & -0.051 \\
\hline Saudi Arabia & 410 & 430 & $0.851 * *$ & 0.225 & $0.444 * *$ & 0.343 \\
\hline Singapore & 606 & 567 & $0.996^{* *}$ & $0.359 * *$ & $0.330^{* *}$ & 0.007 \\
\hline Slovak Republic & 507 & 535 & $0.960 * *$ & 0.003 & -0.056 & 0.069 \\
\hline Slovenia & 513 & 530 & $0.984 * *$ & -0.018 & 0.004 & -0.002 \\
\hline Spain & 482 & 513 & $0.884^{* *}$ & 0.048 & -0.002 & $-0.005^{*}$ \\
\hline Sweden & 504 & 542 & $0.968 * *$ & -0.131 & -0.172 & $-0.021 * *$ \\
\hline UAE & 434 & 539 & $0.974 * *$ & $0.200 * *$ & $0.218^{* *}$ & -0.075 \\
\hline Northern Ireland & 562 & 558 & $0.954 * *$ & 0.071 & 0.020 & 0.019 \\
\hline
\end{tabular}


Table 5.1 (continued)

\begin{tabular}{|c|c|c|c|c|c|c|}
\hline \multirow[t]{2}{*}{$\begin{array}{l}\text { Educational } \\
\text { system }\end{array}$} & \multicolumn{2}{|c|}{$\begin{array}{l}\text { International } \\
\text { averages }\end{array}$} & \multicolumn{3}{|c|}{ Measurement models } & \multirow{2}{*}{$\begin{array}{l}\begin{array}{l}\text { Random slope } \\
\text { models }\end{array} \\
\text { Slope on } \\
\text { InQuaB }\end{array}$} \\
\hline & Math & Read & $\begin{array}{l}\text { Math with } \\
\text { read }\end{array}$ & $\begin{array}{l}\text { Math with } \\
\text { InQuaB }\end{array}$ & $\begin{array}{l}\text { Read with } \\
\text { InQuaB }\end{array}$ & \\
\hline Dubai & 468 & 476 & $0.987 * *$ & $0.244 * *$ & $0.264^{*}$ & -0.302 \\
\hline Abu Dhabi & 417 & 424 & $0.962 * *$ & 0.172 & 0.190 & -0.019 \\
\hline Quebec & 533 & 538 & $0.824 * *$ & -0.073 & 0.115 & -0.083 \\
\hline
\end{tabular}

Note Math = mean of TIMSS 2011 mathematics achievement; Read = mean of PIRLS 2011 reading achievement; Math with Read = class-level correlation between mathematics and reading achievement; Math with InQuaB = class-level correlation between mathematics achievement and instructional quality; Read with InQuaB = class-level correlation between reading achievement and instructional quality; Slope on $\operatorname{InQuaB}=\beta$ value for the regression of InQuaB on the relationship between mathematics and reading achievement

*significant at the 0.05 level

**significant at the 0.01 level

Estimates for residuals are not reported because all residuals were estimated to be 0 , even the significant residuals

reading comprehension on mathematics achievement. In four of the countries (Croatia, Finland, Spain, and Sweden), this was the case. In two of the countries (Austria and the Czech Republic), the influence of InQuaB was positive, meaning that the relationship between reading and mathematics was strengthened. The correlations between InQuaB and reading comprehension and mathematics skills were nonsignificant for all six countries where an effect was observed, indicating that the low-achieving classes in these countries resemble their peers in higher-achieving classes in terms of how they judge the instructional quality.

For the countries with significant positive relations between InQuaB and reading and mathematics achievement, the estimate of the slope on InQuaB was nonsignificant for all cases. The overall picture is mainly one of nonsignificant effects of InQuaB on the latent slope variable. This is probably because there was very little estimated slope variability across classrooms in most countries. This, in turn, is likely because the number of students in each classroom is so limited that it is difficult to achieve sufficient statistical precision in the estimation of slope variability.

\subsection{Discussion and Concluding Remarks}

Overall, a strong correlation between reading and mathematics was observed at the classroom level. However, a significant positive correlation between instructional quality and reading and mathematics was observed in fewer than half the participating educational systems. Moreover, an effect of instructional quality on the relationship between reading comprehension and mathematics skill was observed for 
only six countries, all European. With the exception of Spain, the overall correlation between mathematics and reading achievement at the class level is in the middle range compared to the other participating educational systems (Table 5.1). In all six countries, students scored significantly above the international mean in reading (see Mullis et al. 2012b, p. 38), with reading scores ranging from 513 to 568. Some of the six countries are among the top performers on PIRLS 2011. In comparison, a range of average mathematics achievement was observed (Table 5.1), with Spain and Croatia scoring significantly below average, Sweden at the average, and Austria, the Czech Republic, and Finland significantly above the international average (see Mullis et al. 2012a, p. 90). The six countries where instructional quality had a moderating effect on the relation between reading and mathematics are all educational systems in which reading instruction is more successful compared to mathematics instruction, judging by the international results on TIMSS 2011 and PIRLS 2011.

Mullis et al. (2013), who also used the joint TIMSS and PIRLS database, investigated whether students at different reading levels could cope to the same extent with mathematics items at both high and low reading levels. They found that, in a few educational systems, students at a low reading level performed at similar levels for low- and high-demand reading-level mathematics items, indicating high quality instruction related to the reading aspects of doing mathematics. This research outcome might support our driving hypothesis regarding instructional quality. Overall, students at a low reading level scored significantly lower in mathematics than their peers at a high reading level (Mullis et al. 2013), but in Finland and Sweden, for instance, students at a low reading level not only scored at a similar level for high- and low-reading demand mathematics items, they even raised the success rate, moving from mathematics items with low reading demand to items with a high reading demand. Finland and Sweden were among the few countries where instructional quality weakened the relationship between reading and mathematics. Nonetheless, no direct conclusions should be drawn from Mullis et al. (2013) with respect to the outcomes of our study. Croatia, for instance, where instructional quality significantly weakened the relation between reading and mathematics, is among the countries where there was a remarkable drop in the success rate when low-level readers moved from mathematics items with low reading levels to items with a higher reading level.

The relationship between instructional quality and achievement (Table 5.1) is difficult to interpret. In educational systems where this relationship is negative, low-achieving classes perceive the instruction their teachers provide to be of higher quality than do their higher-achieving peers. Reading instruction should target deep reading strategies and include strategies for comprehending mathematical texts for all students, as proposed by Murnane et al. (2012). Otherwise, it is unlikely that this instruction will provide students with strategies for comprehending mathematical tasks. The student questionnaire items that together measure instructional quality do not address strategy instruction as such. Instead, students are asked about how they conceive their mathematics and reading lessons. Still, it may be argued that students and classes who feel their teacher is easy to understand and interesting, and who 
think they know what their teacher expects of them during lessons report perceived quality in the instruction their teachers deliver. The varying sign and strength of the relationship between instructional quality and achievement across countries suggest that the student assessments are influenced by response styles and other factors that affect the estimated relationship. Further research on this issue is needed.

Some teachers "blame" students' reading level and the amount of text in mathematical tasks for their students' shortcomings with mathematical problem solving (Pearce et al. 2012). Prior research has demonstrated that when comparing the reading and mathematics instruction delivered by primary school class teachers, teachers are usually more skilled in teaching either reading or mathematics; they rarely teach both subjects equally well (Graeber et al. 2012).

Finally, some potential consequences for instruction and policy making should be discussed. First, reading is fundamental to further learning. Students who are better readers seem to be better equipped for learning in other subjects, including mathematics. In the educational systems, a high focus on reading interventions may be a good investment in students' futures and an essential part of their lifelong learning processes. We thus advocate Murnane et al. (2012) view that reading instruction in primary school should include texts from other school subjects, including mathematical texts. However, early emphasis on reading skills is less related to achievement in TIMSS and PIRLS 2011 than teachers' promotion of student engagement (Martin et al. 2013, p. 115). Even after controlling for home background, engaging instruction has a predictive positive effect on achievement. Students engaged in their lessons have higher achievement than students with lower or no engagement.

Thus, active teachers who make sure students know what is expected of them, strive to be easily understood, present content in engaging ways, and generally manage to maintain their students' motivation will positively promote their students' achievements (Martin et al. 2013, p. 115). Clearly, high-quality teaching matters to student learning. According to Scherer and Gustafsson (2015), constructing a differentiated measure for instructional quality at the class level that combines the instructional quality constructs from different subject matter domains could enable detection of different aspects of instructional quality. When the moderating effect of instructional quality on the relationship between reading and mathematics was inconclusive, this is most likely due to a combination of reliability and validity issues in the assessment of instructional quality and the lack of statistical power. Although the outcome of the analysis is inconclusive, the driving hypothesis is not rejected. Instead, more research is needed to further disentangle how instruction might weaken the influence of students' reading comprehension to their mathematical problem solving. This research could take as its point of departure that some educational systems have students at low reading levels that perform equally well on low-reading demand and high-reading demand mathematics items as shown by Mullis et al. (2013) and the outcomes of the analysis reported in this study. 
Open Access This chapter is distributed under the terms of the Creative Commons AttributionNonCommercial 4.0 International License (http://creativecommons.org/licenses/by-nc/4.0/), which permits any noncommercial use, duplication, adaptation, distribution and reproduction in any medium or format, as long as you give appropriate credit to the original author(s) and the source, provide a link to the Creative Commons license and indicate if changes were made.

The images or other third party material in this chapter are included in the work's Creative Commons license, unless indicated otherwise in the credit line; if such material is not included in the work's Creative Commons license and the respective action is not permitted by statutory regulation, users will need to obtain permission from the license holder to duplicate, adapt or reproduce the material.

\section{References}

Abedi, J., \& Lord, C. (2001). The language factors in mathematics tests. Applied Measurement in Education, 14(3), 219-234.

Adelson, J. L., Dickinson, E. R., \& Cunningham, B. C. (2015). Differences in the readingmathematics relationship: A multi-grade, multi-year statewide examination. Learning and Individual Differences, 43, 118-123.

Bernardo, A. B. I. (2005). Language and modelling word problems in mathematics among bilinguals. The Journal of Psychology, 139(5), 413-425.

Björn, P. M., Aunola, K., \& Nurmi, J.-E. (2014). Primary school text comprehension predicts mathematical word problem-solving skills in secondary school. Educational Psychology, 36, 1-16. doi:10.1080/01443410.2014.992392

Cummins, D. D., Kintsch, W., Reusser, K., \& Wiemer, R. (1988). The role of understanding in solving word problems. Cognitive Psychology, 20(4), 405-438.

Fuchs, L. S., Fuchs, D., Compton, D. L., Hamlett, C. L., \& Wang, A. Y. (2015). Is word-problem solving a form of text comprehension? Society for the Scientific Study of Reading, 19(3), 204-223.

Fuentes, P. (1998). Reading comprehension in mathematics. The Clearing House, 72(2), 81-88.

Glenberg, A., Wilford, J., Gibson, B., Goldberg, A., \& Zhu, X. (2012). Improving reading to improve math. Scientific Studies of Reading, 16(4), 316-340.

Graeber, A. O., Newton, K. J., \& Chambliss, M. J. (2012). Crossing the boarders again: Challenges in comparing quality in instruction in mathematics and reading. Teachers College Record, 114, 1-30.

Inoue, N. (2005). The realistic reasons behind unrealistic solutions: The role of interpretive activity in word problem solving. Learning and Instruction, 15, 69-83.

Lesh, R. A., \& Zawojewski, J. (2007). Problem solving and modeling. In F. K. J. Lester (Ed.), Second handbook of research on mathematics teaching and learning (Vol. 2, pp. 763-804). Charlotte, NC: Information Age.

Martin, M. O., Foy, P., Mullis, I. V. S., \& O’Dwyer, L. M. (2013). Effective schools in reading, mathematics and science at the fourth grade. In M. O. Martin \& I. V. S. Mullis (Eds.), TIMSS and PIRLS 2011: Relationships among reading, mathematics, and science achievement-implications for early learning (pp. 109-178). Boston, MA: TIMSS \& PIRLS International Study Center.

Martin, M. O., \& Mullis, I. V. S. (2013). TIMSS and PIRLS 2011: Relationships among reading, mathematics, and science achievement at the fourth grade-Implications for early learning. Boston, MA: TIMSS \& PIRLS International Study Center.

Moreau, S., \& Coquin-Viennot, D. (2003). Comprehension of arithmetic word problems by fifth-grade pupils: Representations and selection of information. British Journal of Educational Psychology, 73(1), 109-121. 
Mullis, I. V. S., \& Martin, M. O. (2013). TIMSS and PIRLS 2011: Relationships among reading, mathematics, and science achievement-implications for early learning. In M. O. Martin \& I. V. S. Mullis (Eds.), TIMSS and PIRLS 2011: Relationships among reading, mathematics, and science achievement-implications for early learning (pp. 1-11). Boston, MA: TIMSS \& PIRLS International Study Center.

Mullis, I. V. S., Martin, A. J., Kennedy, A. M., Trong, L., \& Sainsbury, M. (2009a). PIRLS 2011 assessment framework. Chestnut Hill, MA: TIMSS \& PIRLS International Study Center.

Mullis, I. V. S., Martin, M. O., Ruddock, G. J., O’Sullivan, C. Y., \& Preuschoff, C. (2009b). TIMSS 2011 assessment frameworks. Boston, MA: TIMSS \& PIRLS International Study Center.

Mullis, I. V. S., Martin, M. O., Foy, P., \& Arora, A. (2012a). TIMSS 2011 international results in Mathematics. Boston, MA: TIMSS \& PIRLS International Study Center.

Mullis, I. V. S., Martin, A. J., Foy, P., \& Drucker, K. T. (2012b). PIRLS 2011 international results in reading. Chestnut Hill, MA: TIMSS \& PIRLS International Study Center.

Mullis, I. V. S., Martin, M. O., \& Foy, P. (2013). The impact of reading ability on TIMSS mathematics and science achievement at the fourth grade: An analysis by item reading demands. In M. O. Martin \& I. V. S. Mullis (Eds.), TIMSS and PIRLS 2011: Relationships among reading, mathematics, and science achievement-implications for early learning (pp. 67-108). Boston, MA: TIMSS \& PIRLS International Study Center.

Murnane, R., Sawhill, I., \& Snow, C. (2012). Literacy challenges for the twenty-first century: Introducing the issue. The Future of Children, 22(2), 3-15.

Muthén, L., \& Muthén, B. (1998-2012). Mplus user's guide (7th Edn.). Los Angeles, CA: Muthén \& Muthén.

Niss, M., \& Højgaard, T. (2011). Competencies and mathematical learning. Ideas and inspiration for the development of mathematics teaching and learning in Denmark (English ed.). Roskilde, Denmark: IMFUMFA.

Nortvedt, G. A. (2010). Understanding and solving multistep arithmetic word problems. Nordic Studies in Mathematics Education, 15(3), 23-50.

Nortvedt, G. A. (2011). Coping strategies applied to comprehend multistep arithmetic word problems by students with above-average numeracy skills and below-average reading skills. Journal for Mathematical Behavior, 30(3), 255-269. doi:10.1016/j.jmathb.2011.04.003

Österholm, M. (2005). Characterizing reading comprehension of mathematical texts. Educational Studies in Mathematics, 63, 325-346.

Palm, T. (2008). Impact of authenticity on sense making in word problem solving. Educational Studies in Mathematics, 67(1), 37-58.

Pearce, D. L., Bruun, F., Skinner, K., \& Lopez-Mohler, C. (2012). What teachers say about student difficulties solving mathematical word problems in Grades 2-5. International Electronic Journal of Mathematics Education, 8(1), 1-17.

Reusser, K., \& Stebler, R. (1997). Every word problem has a solution: The social rationality of mathematical modeling in schools. Learning and Instruction, 7(4), 309-327.

Roth, W.-M. (2009). On the problematic of word problems-language and the world we inhabit. In L. Verschaffel, B. Greer, W. Van Dooren, \& S. Mukhopadhyay (Eds.), Words and worlds. Modelling verbal descriptions of situations (pp. 55-69). Rotterdam, The Netherlands: Sense.

Säljö, R., Riesbeck, E., \& Wyndhamn, J. (2009). Learning to model: Coordinating natural language and mathematical operations when solving word problems. In L. Verschaffel, B. Greer, W. Van Dooren, \& S. Mukhopadhyay (Eds.), Words and worlds. Modelling verbal descriptions of situations (pp. 177-193). Rotterdam, The Netherlands: Sense.

Scherer, R., \& Gustafsson, J. E. (2015). Student assessment of teaching as a source of information about aspects of teaching quality in multiple subject domains: An application of multilevel bifactor structural equation modeling. Frontiers in Psychology, 6, 1550.

Schoenfeld, A. H. (1992). Learning to think mathematically: Problem solving, metacognition, and sense-making in mathematics. In D. A. Grouws (Ed.), Handbook of research on mathematics teaching and learning (pp. 334-370). New York, NY: MacMillan. 
Snow, C. E. (2002). Reading for understanding: Toward a $R \& D$ program in reading comprehension. Pittsburg, PA: RAND Education.

Thevenot, C., Devidal, M., Barrouillet, P., \& Fayol, M. (2007). Why does placing the question before an arithmetic word problem improve performance? A situation model account. Quarterly Journal of Experimental Psychology, 60(1), 43-56.

Verschaffel, L., De Corte, E., \& Greer, B. (2000). Making sense of word problems. Lisse, The Netherlands: Swets \& Zeitlinger.

Vicente, S., Orrantia, J., \& Verschaffel, L. (2007). Influence of situational and conceptual rewording on word problem solving. British Journal of Educational Psychology, 77, 829-848.

Vilenius-Tuohimaa, P. M., Aunola, K., \& Nurmi, J.-E. (2008). The association between mathematical word problems and reading comprehension. Educational Psychology, 28(4), 409-426.

Vista, A. (2013). The role of reading comprehension in maths achievement growth: Investigating the magnitude and mechanism of the mediating effect on maths achievement in Australian classrooms. International Journal of Educational Research, 62(6), 21-35.

von Davier, M., Gonzalez, E., \& Mislevy, R. (2009). What are plausible values and why are they useful? IERI Monograph Series, 2, 9-36. 